\title{
Data acquisition, validation and forecasting for a combined sewer network
}

\author{
É. Crobeddu \& S. Bennis \\ École de Technologie Supérieure, \\ Département de Génie de la Construction, Québec, Canada
}

\begin{abstract}
The scope of this work is the development of a computerized tool, named PREVAL, for day-to-day sewer network management. This tool allows: 1) to simulate hydrographs and pollutographs at the outlet of an urban catchment basin and through control devices, 2) to make the validation and the filtering of measurement data by using univariate or multivariate methods based on material or analytical redundancy, 3 ) to provide hydraulic and hydrological models with reliable data for the calibration stage, 4) to evaluate combined sewer overflows in terms of quality and quantity and to check the conformity of the operation of overflow devices with respect to prescribed constraints. PREVAL is the result of a close cooperation between École de Technologie Supérieure, Hydro-Québec and various partners such as the cities of Montreal, Laval and Verdun.

Keywords: control, overflow structures, pollution, validation.
\end{abstract}

\section{Introduction}

The management of sullage discharge into a natural environment requires a qualitative and quantitative assessment of the outflow. The estimation of the quantity and quality of sullage is based on measurements and on calibrated hydraulic and hydrological models. The reliability of sullage discharge assessment can be warranted only by the validation of discharge flow rate data.

\subsection{Quantitative assessment}

The quantitative assessment consists in estimating the frequency and the volume of the sullage discharged into the natural environment by control devices. The 
estimation of the quantity and quality of sullage is based on measurements and on calibrated hydraulic and hydrological models. The direct measurement of discharge is obtained by flow rate or height measuring instruments (BertrandKrajewski et al. [6]) installed at the exit of control devices. Hydraulic and hydrological models provide theoretical estimations of sullage discharged into the natural environment. The theoretical computations require that the functioning of the control devices be known. The discharge laws are not always adapted to the control devices used in sewer networks (Zug et al. [10]). They usually necessitate specific calibration.

The validity of an assessment depends on the validity of the data obtained by measurements or by models. Measurement data may be affected by errors due to instrument disorders or an inadequate environment. Hydraulic and hydrological models require data which have been obtained and validated for their calibration. The experimental errors in pluviometer and hydrometer data are combined with the shortcomings of the model in producing the total errors of the forecasted values. The validation of the quantitative assessment of the discharge requires the validation of the data obtained by measurements or by models.

\subsection{Review and validation of the data}

Environmental regulation constraints and social pressure prompt managers to better know the working of their networks. The instrumentation of a network allows for an efficient control. It consists in providing the network with gauges and instruments for supervision. The obtained data are stored locally or centrally. This information is important but subject to errors. Among the numerous sources of errors, one may mention:

- The lack of maintenance or improper conditions of utilization of the gauges causes biased and aberrant values in data series.

- The problems of transmission and storage of information are causes of missing data.

The use of instruments produces a great quantity of information which cannot be dealt with by manual procedures.

The use of computerized methods is therefore a necessity. In practice however, the verification and validation of environmental data are either missing or are not subject to an automated procedure. The time needed for the validation and its cost become then very important. As a consequence, the validation of environmental data by the managers of urban sewer networks tends to be a summary and improvised procedure. Scientific and technological developments are recent, as far as the automated validation of urban environmental data is concerned. Most of them rely on the use of statistical tools (Berrada et al. [5]), (Bennis et al. [3]), (Bennis et al. [1]), (Bennis et al. [2]). Some of the validation procedures make a direct use of material and analytical redundancy, relying on the manager's know-how (Blanchet et al. [7]). The occurrence of missing data in chronological series is a common problem. Techniques for the rehabilitation of missing data have been developed (Bennis et al. [2]). Little research has been done as far as the automated review (pre-validation) of environmental data is concerned (Mourad and Bertrand-Krajewski [8]). 


\section{PREVAL program}

\subsection{Introduction}

Managers need efficient and comprehensive tools in order to control discharge. These requirements are not simultaneously fulfilled by present management tools. PREVAL was developed to overcome this shortage by allowing forecasting and validating hydraulic data for the control of pollution discharged into the natural environment.

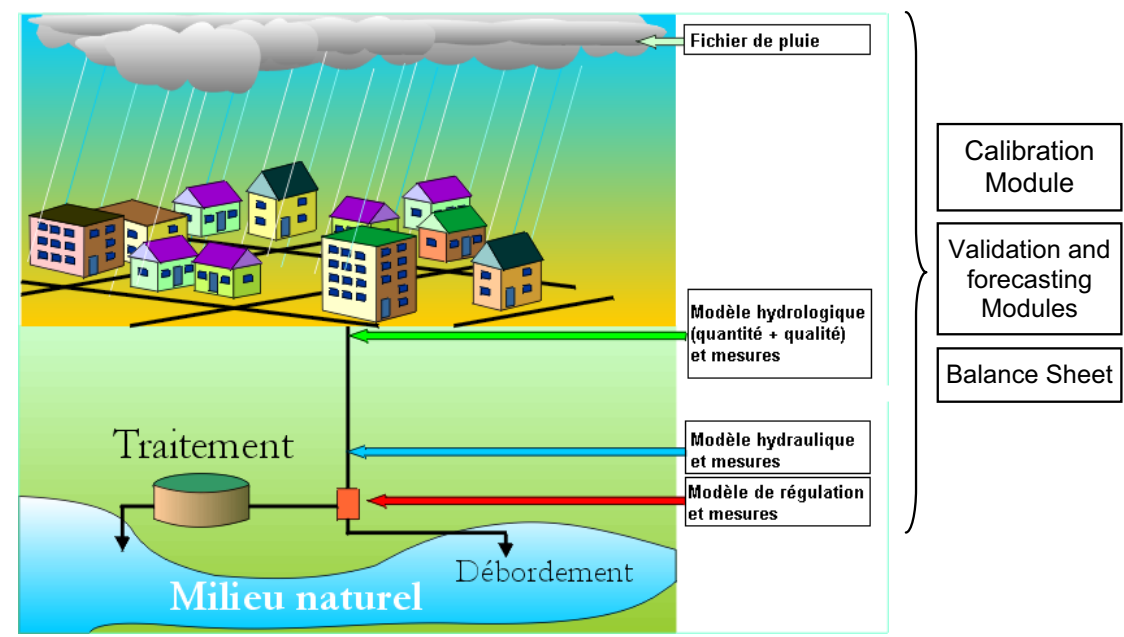

Figure 1: Configuration of the urban sanitation system.

The tool consists of three modules: a hydrological module, a hydraulic module and a validation module. These modules may be used together or independently from one another.

\subsection{Model design tools}

\subsubsection{Tools for hydrological models}

The hydrological module represents globally the runoff phenomena on a drainage basin and the flow process in pipelines. The transportation of pollutants and in particular of suspended matter is obtained by a modified "Rating Curve" model (Temimi and Bennis [9]). This model takes into account the variable phase shifts often encountered between hydrographs and pollutographs. The generated hydrographs and pollutographs are useful for the evaluation of the hydraulic performance of an existing network from the viewpoint of overflow while they are required to generate the analytical redundancy needed for the validation of hydrological data. 


\subsubsection{Tools for hydraulic models}

The purpose of the hydraulic simulation module is to investigate and follow up the flow process over weirs. Contrary to existing commercial programs, our purpose is not to develop a detailed model for a given system (sewer network + control devices). In our hydraulic module, a global approach is preferred to represent the various overflow devices which may be encountered in sewer networks. The Theoretical study has been completed by laboratory tests in order to validate the selected models.

\subsection{Analysis and computation tools}

\subsubsection{Validation and forecasting modules}

Validation is an essential step for the control of the pollution discharged by overflow weirs. The validation module includes innovating mathematical procedures allowing automated data processing. Two types of validation methods are integrated for the corrections needed by the noisy and aberrant values of data series. The univariate validation methods consist of statistical procedures adapted to single data series (Berrada et al. [5]). Multivariate validation methods, on the other hand, allow processing several strongly correlated data series (Bennis and Kang [2]). The multivariate methods are especially well adapted to the handling of data series generated by analytical or material redundancy. The validation module includes methods for the estimation of missing data (Bennis et al. [3]). It possesses several powerful filters (standard regression, Kalman filter, principal component analyses, ARIMA). The validation module includes forecasting methods for hydraulic data. Forecasting is obtained by the ARMAX and ARMA models.

\subsubsection{Calibration and balance-sheet modules}

The calibration of the parameters pertaining to the hydraulic and hydrological models is obtained with the help of the calibration module. This module uses standard regression tools or the Kalman filter. The balance-sheet module comprises statistical procedures for the analysis of overflow frequency as well as of the overflowing masses and volumes. It is thus possible to insure the followup of the performance of a sewer network system over long periods.

\section{Testing of the PREVAL program}

PREVAL has been tested on Sector 1 of the combined sewer network of the borough of Verdun. This portion the Verdun basin extends over an area of 177 ha and has $40 \%$ permeability. The test of PREVAL proceeded in three phases. The first phase consisted in producing a hydrological simulation and in using the simulation results for the validation of the measured data. In the second phase, the validated measured data were used to determine the volumes of water and the quantities of pollutants overflowing into the natural environment. 


\subsubsection{Hydrological simulation and validation}

PREVAL was used for the calibration of the hydrological model. The quality of the simulation has been evaluated on the basis of four performance indicators:

- The NASH coefficient $: N A S H=1-\frac{\sum_{i=1}^{n}\left(Q_{i}^{\text {Measured }}-Q_{i}^{\text {Simulated }}\right)^{2}}{\sum_{i=1}^{n}\left(Q_{i}^{\text {Measured }}-Q_{i}^{\text {Mean }}\right)^{2}}$

- The volume ratio

$$
: R V=\frac{\text { total volume of simulated runoff }}{\text { total volume of meaured runoff }}
$$

- The peak ratio

$$
: R P=\frac{Q_{\text {Max }}^{\text {Simulated }}}{Q_{\text {Max }}^{\text {Measued }}}
$$

- The peak flow synchronism : $\Delta \mathrm{T}=$ time delay between measured and simulated peak flow rates.

The results of the simulations are shown in table 1 .

Table 1: $\quad$ Results of hydrological simulations obtained by PREVAL.

\begin{tabular}{|c|c|c|c|c|}
\hline Events & RV & RP & NASH & $\Delta$ T (min) \\
\hline $30-09-1999$ & 1,11 & 0.90 & 0,89 & 5 \\
\hline $13-10-1999$ & 1,1 & 1.231 & 0.84 & 5 \\
\hline $16-08-2000$ & 1,0 & 0.99 & 0.81 & 5 \\
\hline $23-08-2000$ & 0,83 & 0.98 & 0.70 & 10 \\
\hline
\end{tabular}

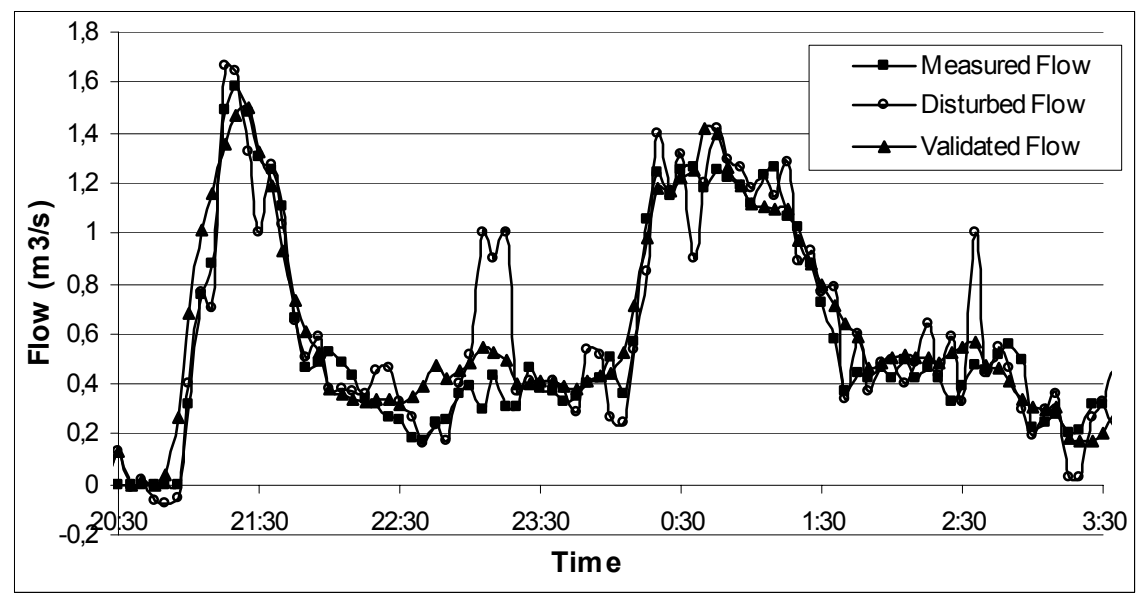

Figure 2: $\quad$ Measured, noisy and validated hydrographs of October 131999.

The hydrological model used in PREVAL appears to be a satisfactory tool for the simulation of hydrographs at the exit of an urban basin. It is therefore 
possible to rely on simulated hydrographs for the multivariate validation of measured flow rates. The events of October 131999 and of August 162000 have been selected for the sake of demonstration. White noise having a variance respectively of $10 \%$ and $20 \%$ has been added to the measured flow values. Moreover, aberrant values having $\mathrm{W}, \mathrm{U}$ and $\mathrm{A}$ shapes have been inserted to simulate temporary gauge failures. A multivariate validation was thereafter applied using PREVAL. The validation results are shown in figure 2 and figure 3 .

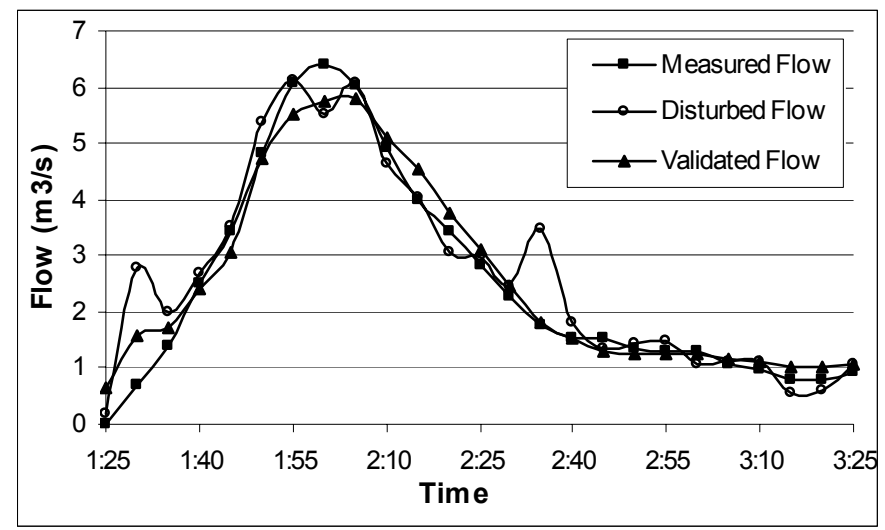

Figure 3: $\quad$ Measured, noisy and validated hydrographs of August 161999.

The PREVAL program has attenuated the noise and suppressed aberrant values. PREVAL corrected the noisy data sequence on the basis of the information provided by the simulated flow rates. Validation which would normally require a manual procedure based on empirical assumptions can now be automated and is governed by physical and statistical criteria

\subsubsection{Hydraulic simulation}

A control system similar to the one found at the exit of the Verdun basin has been configured in PREVAL. It consists of two rectangular flood-gates $(0,914 \mathrm{~m}$ wide, $0,914 \mathrm{~m}$ high) controlling the flow toward the station. It is located at the end of a conduit having a $2 \mathrm{~m}$ wide rectangular section and a $0,1 \%$ slope. The excess overflow is discharged into the natural environment by a pumping station equipped with 6 pumps in parallel, each discharging $0,6 \mathrm{~m}^{3} / \mathrm{s}$. The pollutograph of the suspended matter concentrations for the event of August 162000 has been measured at the upstream end of the control system. PREVAL was able to compute the hydrograph and the pollutograph for the overflow discharged into the natural surroundings for a given gate closure scenario during the rainfall event. The results of the hydraulic simulation by PREVAL are shown in figure 4, taking into account the measured flow rates and the previously obtained noisy and validated data. 


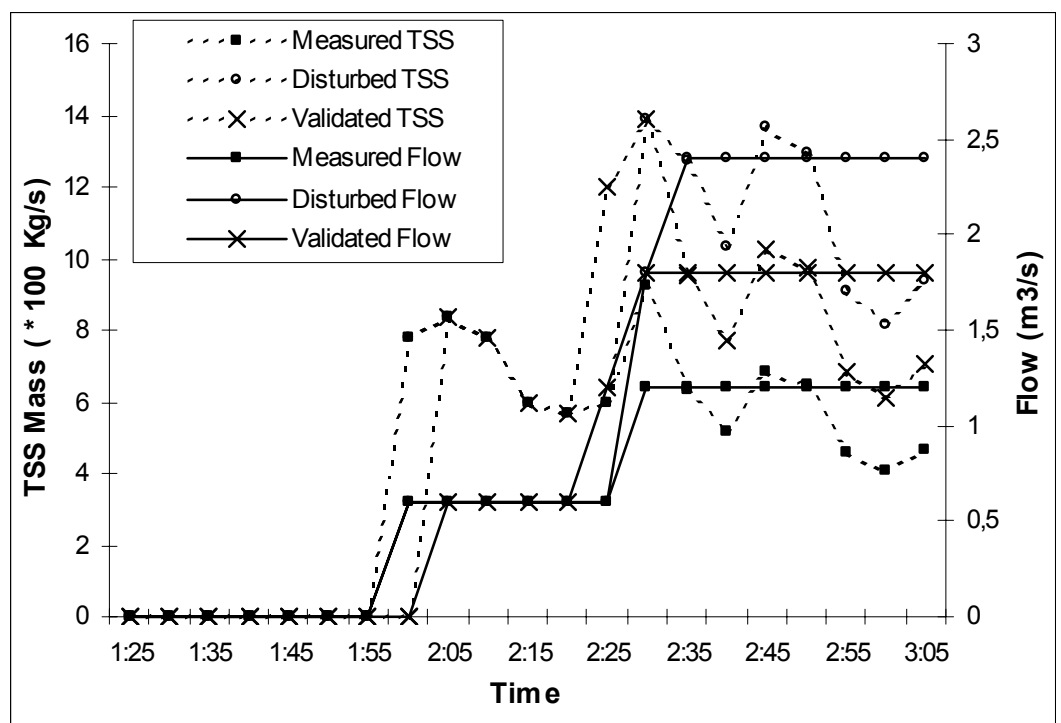

Figure 4: Hydrographs and pollutographs of discharge into natural environment

Figure 4 shows that the noisy measured flow data produced an overestimation of the flow rates and pollutant loads of the flow discharged into the natural surroundings. Validated flow rates produced discharge loads and flow rates closer to the true values.

\section{Conclusion}

PREVAL is a complete and modular tool satisfying present needs of sewer network managers. In differs from other programs found on the market by the fact that the routines for the simulation of hydraulic phenomena, for validation, for forecasting and for balance-sheet calculations are included in a single program. It offers great flexibility due to its modular structure. Each module can be used independently from the others during an analysis, according to the user's specific needs. PREVAL is a particularly efficient tool for the preparation of reliable balance sheets dealing with pollutant discharge by overflow weirs. It is also an efficient tool for the follow-up of the performance and functioning of a sewer network. The application of PREVAL to the Verdun site was a conclusive and promising exercise. The hydraulic phenomena have been correctly simulated and the validation of the measured data has allowed one to realistically assess the amount of pollution discharged to the natural environment. 


\section{References}

[1] Bennis, S., Berrada, F. and Bernard, F. (2000a). Méthodologie de validation des données hydrométriques en temps réel dans un réseau d'assainnissement urbain. Revue des Sciences de l'Eau, 13(4), 483-498.

[2] Bennis, S., Berrada, F. and Kang, N. (1995). Improving single variable and multivariable techniques for estimating missing hydrological data. Journal of Hydrology, 191(1-4), 87-105.

[3] Bennis, S., Cote, S. and Kang, N. (1996). Validation des données hydrométriques par des techniques multivariées de filtrage. Canadian Journal of Civil Engineering, 23(1), 218-230.

[4] Bennis, S. and Kang, N. (2000b). Multivariate technique for validating historical hydrometric data with readundant measurements. Journal of Nordic Hydrology, 31(2), 107-122.

[5] Berrada, F., Gagnon, L. and Bennis, S. (1996). Validation des données hydrométriques par des techniques univariées de filtrage. Revue Canadienne de Génie Civil, 23, 872-892.

[6] Bertrand-Krajewski, J. L., Laplace, D., Joannis, C. and Chebbo, G. (2000). Mesures en hydrologie urbaine et assainissement. Tec \& Toc, Lavoisier, Paris.

[7] Blanchet, F., Breuil, B. and Viola, A. (1998). Aquaval: Un système d'acquisition et de validation automatique des mesures en réseau d'assainissement. Exemple d'application sur le département de la Seine Saint-Denis. Novatech 1998. $3^{e}$ conférence internationale sur les nouvelles technologies en assainissement pluvial, Lyon 4-6 mai 1998, 155-162.

[8] Mourad, M. and Bertrand-Krajewski, J. L. (2002). A method for automatic validation of long time series of data in urban hydrology. Water Science and Technology, 45(4-5), 263-270.

[9] Temimi, M. and Bennis, S. (2002). Prévision en temps réel des charges de polluants dans un réseau d'assainissement urbain. Revue des Sciences de l'Eau, 15(3), 661-675.

[10] Zug, M., Vazquez, J., Bellefleur, D. and Issanchou, E. (2001). Les déversoirs d'orage: Connaît-on les ouvrages de nos réseaux et comment ils fonctionnement? $4^{\text {ieme }}$ conférence internationale NOVATECH, Lyon, 205212. 